Check for updates

Cite this: Soft Matter, 2018, 14,5654

Received 20th April 2018, Accepted 18th June 2018

DOI: $10.1039 / \mathrm{c} 8 \mathrm{sm} 00821 \mathrm{c}$

rsc.li/soft-matter-journal

\section{A new twist on sea silk: the peculiar protein ultrastructure of fan shell and pearl oyster byssus $\dagger$}

\author{
Delphine Pasche, (ID *a Nils Horbelt, (DD ${ }^{a}$ Frédéric Marin, (D) b Sébastien Motreuil, (ID) ${ }^{b}$ \\ Elena Macías-Sánchez, (iD a Giuseppe Falini, (D) c Dong Soo Hwang, iD d \\ Peter Fratzl (iD *a and Matthew James Harrington (iD *ae
}

\begin{abstract}
Numerous mussel species produce byssal threads - tough proteinaceous fibers, which anchor mussels in aquatic habitats. Byssal threads from Mytilus species, which are comprised of modified collagen proteins - have become a veritable archetype for bio-inspired polymers due to their self-healing properties. However, threads from different species are comparatively much less understood. In particular, the byssus of Pinna nobilis comprises thousands of fine fibers utilized by humans for millennia to fashion lightweight golden fabrics known as sea silk. $P$. nobilis is very different from Mytilus from an ecological, morphological and evolutionary point of view and it stands to reason that the structurefunction relationships of its byssus are distinct. Here, we performed compositional analysis, X-ray diffraction (XRD) and transmission electron microscopy (TEM) to investigate byssal threads of $P$. nobilis, as well as a closely related bivalve species (Atrina pectinata) and a distantly related one (Pinctada fucata). This comparative investigation revealed that all three threads share a similar molecular superstructure comprised of globular proteins organized helically into nanofibrils, which is completely distinct from the Mytilus thread ultrastructure, and more akin to the supramolecular organization of bacterial pili and F-actin. This unexpected discovery hints at a possible divergence in byssus evolution in Pinnidae mussels, perhaps related to selective pressures in their respective ecological niches.
\end{abstract}

\section{Introduction}

Many organisms fabricate polymeric fibers from protein building blocks, which function outside the body in various roles such as prey capture, defense and attachment. ${ }^{1}$ Some natural fibers, such as silk and mussel byssus, have become important biological role models for inspiring development of advanced biomimetic materials. ${ }^{2-4}$ In general, the enormous biological diversity of materials produced by different species offers a range of different material solutions and potentially transformative structure-function paradigms. ${ }^{5-8}$ Along these lines, comparative investigations of analogous biological materials produced by closely and distantly related species is essential for elucidating

\footnotetext{
${ }^{a}$ Department of Biomaterials, Max Planck Institute of Colloids and Interfaces, Potsdam 14424, Germany. E-mail: depasche@gmail.com, peter.fratzl@mpikg.mpg.de

${ }^{b}$ UMR CNRS 6282 Biogéosciences, Université de Bourgogne - Franche-Comté, Dijon 21000, France

${ }^{c}$ Department of Chemistry, University of Bologna, Bologna 40126, Italy

${ }^{d}$ School of Environmental Science and Engineering, Pohang University of Science and Technology, Pohang, South Korea

${ }^{e}$ Department of Chemistry, McGill University, 801 Sherbrooke Street West, Montreal, Quebec H3A 0B8, Canada. E-mail: matt.harrington@mcgill.ca

$\dagger$ Electronic supplementary information (ESI) available. See DOI: 10.1039/c8sm00821c
}

biological materials design. This approach has been critical to understanding the underlying design principles of spider and insect silks, ${ }^{6}$ and clearly, holds great potential for better understanding the mussel byssus. ${ }^{9,10}$ The byssus is a set of protein holdfast fibers that helps mussels survive strong marine currents and resist predation. Mytilus mussel byssus has received a great deal of attention due to its self-healing capacity, high toughness and strong underwater adhesion. ${ }^{11-13}$ Its study has not only increased the understanding of the relationship between protein structure and macroscale properties, ${ }^{14,15}$ but the discovery of distinct chemical features in the byssal thread proteins from Mytilus spp. (e.g. 3,4-dihydroxyphenylalanine (DOPA)) has inspired the development of new synthetic materials such as adhesives for fetal surgery ${ }^{2}$ and self-healing polymers. ${ }^{16,17}$

The self-healing capacity and remarkable mechanical performance of Mytilus byssal threads originate from their peculiar combination of protein domains with specific secondary structures and chemical features - they are primarily comprised of protein building blocks consisting of collagen domains flanked on both ends by extensible cross beta-sheet domains, which are mechanically stabilized by histidine-metal coordination. ${ }^{14,18,19}$ However, Mytilus are not the only byssus-producing mussels analogous to silks, byssus from different species exhibits a wide range of compositions, structures and putative functions. 


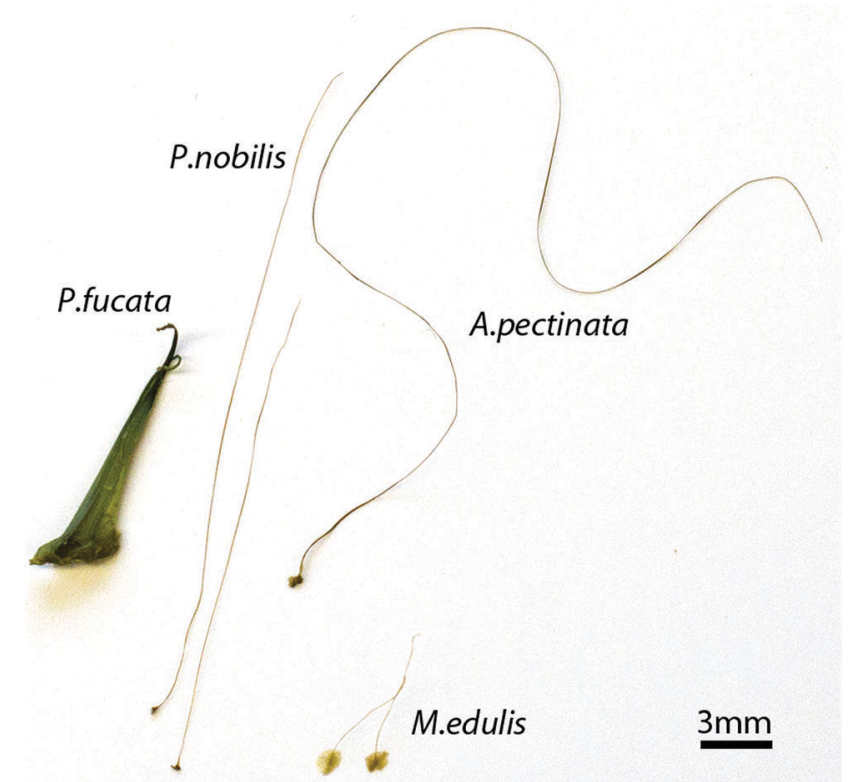

Fig. 1 Comparative morphology of different byssal threads. Morphological variation between byssal threads investigated in this study, including fan shells (P. nobilis and A. pectinata), pearl oysters (P. fucata) and blue mussels (M. edulis).

For example, the byssus of the giant clam Tridacna maxima is comprised of four-stranded coiled-coil proteins, ${ }^{20}$ while Anomia oysters even possess a calcified byssus. ${ }^{21}$ In addition to these species, the byssus of the fan mussel, Pinna nobilis (Fig. 1) is of particular interest because it has been used for embroidery of valuable lightweight fabrics for several millennia, renowned in ancient times for their golden color. ${ }^{22,23}$ Presently, $P$. nobilis is a protected species due to overfishing and massive destruction by boat anchors, which makes it difficult to acquire samples for investigation. However, a recently published study ${ }^{9}$ compared the tensile properties of byssal threads from P. nobilis to threads from Mytilus, Perna and Xenostrobus species. While the stress-strain curve superficially resembles Mytilus spp. threads in its general shape, $P$. nobilis threads exhibited lower extensibility, strength and yield strain and higher stiffness, which the authors attributed to observed differences in the amino acid and elemental composition of the fibers. While this is a compelling hypothesis, there is currently an enormous lack of knowledge about the nano- and micro-scale hierarchical structure of $P$. nobilis byssal threads, ${ }^{24-26}$ which is known to play a critical role in the structure-function relationships of Mytilus threads. ${ }^{18}$

Here, we aim to elucidate the superstructural organization of proteins in $P$. nobilis byssal threads and compare it to threads from related bivalve species, in order to assess the relationship between byssus structure and evolutionary function. Therefore, we performed an in-depth comparative investigation of byssal threads from Pinna nobilis, Atrina pectinata, and Pinctada fucata and compared these findings to that of the well-studied Mytilus byssal threads (Fig. 1). The evolutionary relationship between the four mussel species, which all belong to the Pteriomorphia subclass of bivalves, is depicted in Fig. 2, indicating that Mytilus mussels, belonging to the Mytiloida order, are distantly related to the other three species which all belong to the order Ostreida. Within the Ostreida order, pearl oysters (Pinctada) and fan shells (Atrina and Pinna) belong to two different superfamilies (Pterioidea and Pinnoidea). A. pectinata and P. nobilis are the most closely related species in this study, both belonging to the Pinnidae family, thus, providing a range of different levels of relationships between the studied byssal threads. In line with these taxonomic divergences, these mussels also live in very different environments: Mytilus specimens are found in intertidal areas where they endure crashing waves, whereas Ostreida members live in calmer waters. The fan shell mussels from

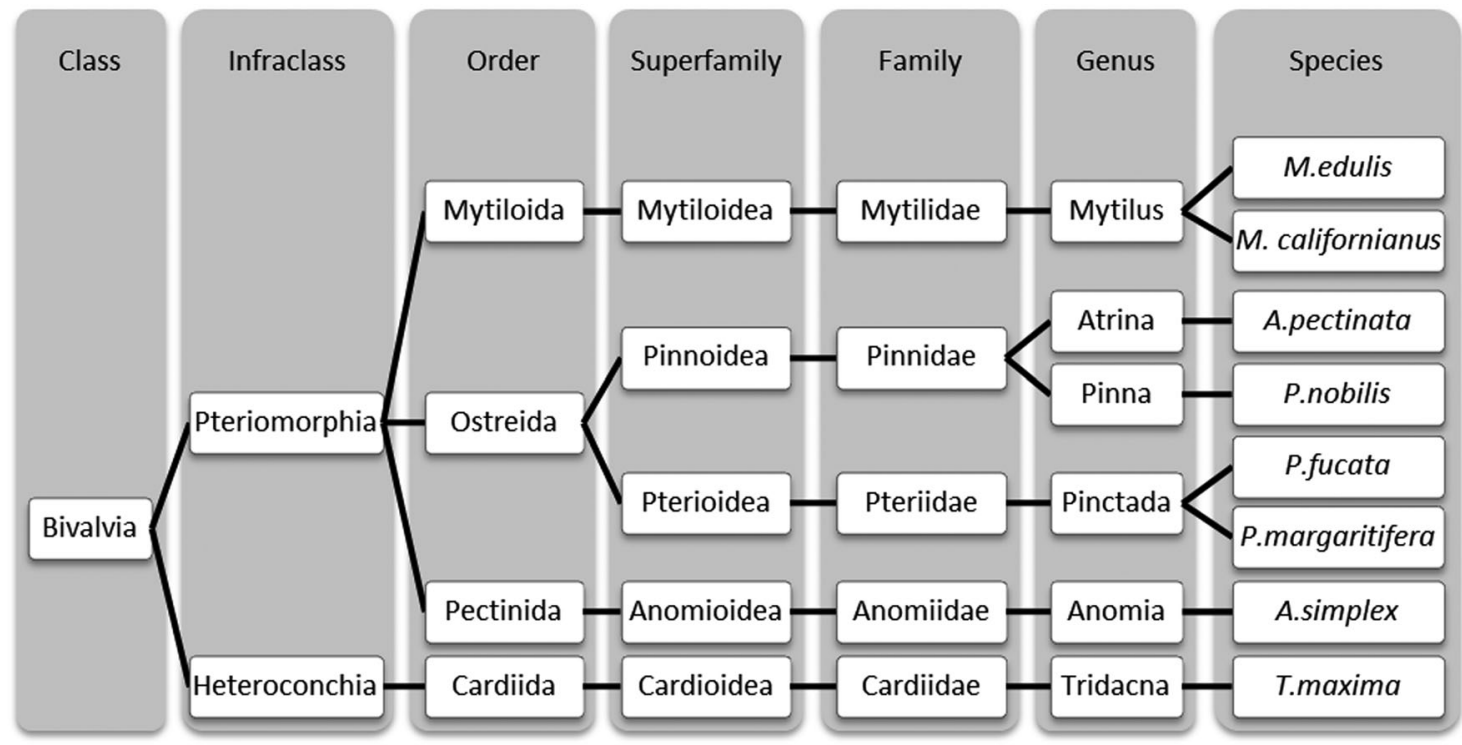

Fig. 2 Taxonomic classification of some byssus-producing bivalves. Classification of different mussels whose byssus structure has been studied thus far, according to Bieler et al. ${ }^{30}$ For simplification, some classification steps were omitted. 
the Mediterranean Sea ( $P$. nobilis) and from the West Pacific (A. pectinata) are very large mussels (up to $1 \mathrm{~m}$ and $0.5 \mathrm{~m}$, respectively). They live partially buried in sandy areas, where their byssus acts more like anchoring plant roots, which is in stark contrast to Mytilus mussels which anchor to hard substratum in the wave-swept rocky intertidal zone. $P$. fucata oysters have a size up to $8.5 \mathrm{~cm}^{27}$ and live in coral reefs in protected areas of the Indo-Pacific ocean. While little is known about the proteins comprising the threads of $P$. nobilis and A. pectinata, $P$. fucata threads are reported to contain a thrombospondin-like protein stabilized by $\mathrm{Ca}^{2+},{ }^{28,29}$ which greatly contrasts the collagen-based byssus of Mytilus spp.

In order to conduct a comparative investigation of the byssus ultrastructure from these species, we utilized a range of techniques including compositional analysis, X-ray scattering and transmission electron microscopy. These reveal that byssal threads of all three species are comprised of a peculiar organization of globular proteins densely packed into nano-fibers and exhibiting a helical superstructure. This helical arrangement has similarities with F-actin and bacterial pili; however, the fact that these helical filaments are organized into a macroscopic fibrous material clearly differentiates the Pinnidae byssus. This highly unusual finding provides insights into how byssus structure is related to evolution and habitat, and also provides important new insights into the role of structural and compositional differences underlying the mechanical differences between P. nobilis and Mytilus spp. byssal threads. Along these lines, it may also provide a new bio-inspired paradigm for producing high-performance polymeric fibers.

\section{Materials and methods}

P. nobilis threads were collected from the wild in the bay of Villefranche-sur-mer, France and between the two Lérins Islands, France. Because $P$. nobilis is strongly protected (European Directive 92/43/CEE), prior to collection, all necessary permits were acquired from DDTM (Direction Départementale des Territoires et de la Mer, J. Banus) of Alpes-Maritimes department. Byssal threads were collected on site, without killing the animals. P. fucata and A. pectinata threads were collected in Namhae, Gyeongnam, South Korea. Mytilus edulis mussels were collected from the North Sea and kept in a saltwater aquarium at $16{ }^{\circ} \mathrm{C}$. Freshly grown threads were collected from the tank-grown mussels. All threads were stored in Milli-Q water prior to measuring.

\section{Inductively coupled plasma optical emission spectrometry}

For metal content determination, approximately $5 \mathrm{mg}$ of threads were freeze-dried and weighed prior to dissolution in $2 \mathrm{ml}$ aqua regia overnight and heating at $180{ }^{\circ} \mathrm{C}$ for 1 hour. The metal content was measured with inductively coupled plasma optical emission spectrometry (ICP-OES, PerkinElmer OPTIMA 8000) calibrated with a set of calibration standards in aqua regia. An independent standard in aqua regia was used to check calibration and stability of the measurement.

\section{Amino acid analysis}

Amino acid analysis was performed using 1-2 mg of freeze-dried threads, which were hydrolyzed for $24 \mathrm{~h}$ in $6 \mathrm{~N} \mathrm{HCl}$ with $10 \%$ phenol at $110{ }^{\circ} \mathrm{C}$ under vacuum. The amino acid composition of the samples was analyzed using a post-column ninhydrin-based amino acid analyzer (Sykam S433, Fürstenfeldbruck, Germany).

\section{X-ray diffraction (XRD)}

For XRD experiments, threads were glued across a hole on a rigid plastic frame. Drying was minimized by placing threads between a Kapton foil with a hydrated tissue present. Wide and small angle X-ray diffraction (WAXD and SAXD) measurements were conducted at BESSY II Berlin (Elektronenspeicherring Gesellschaft m.b.H., Berlin, Germany) MuSpot beamline. ${ }^{31}$ The X-ray wavelength was $0.82565 \AA$ and the beam diameter was $50 \mu \mathrm{m}$. The diffraction patterns were collected on a $2 \mathrm{D}$ CCD detector (MarMosaic 225, Mar USA, Evanston, USA) with a pixel size of $73.24 \mu \mathrm{m}$ and a frame size of $3072 \times 3072$ pixels. Diffraction patterns were processed with dpdak, an open source XRD analysis tool. ${ }^{32}$ Confirmation and refinement of the structure were done using the HELIX software, ${ }^{33}$ which is a simple tool simulating diffraction patterns of helical structures from a set of parameters introduced by the user.

\section{Transmission electron microscopy (TEM)}

Threads were air-dried prior to embedding in LR White resin (Agar), polymerized at $60{ }^{\circ} \mathrm{C}$ for 3 days and then cut into $100 \mathrm{~nm}$ slices (Leica Ultracut UCT). Grids were post-stained with 1-2\% uranyl acetate (aqueous solution) for 1-10 $\mathrm{min}$ and briefly rinsed in miliQ water. Bright field TEM images were obtained with a Zeiss EM 912 Omega at $120 \mathrm{kV}$ and a Jeol JEM-ARM200F at $200 \mathrm{kV}$.

\section{Results}

\section{Byssus composition (ICP-OES and amino acid analysis)}

We used amino acid analysis to investigate the protein composition of A. pectinata, P. fucata and P. nobilis byssus and ICP to characterize their inorganic content, and then compared the results with Mytilus byssus (Fig. 3a). Amino acid analysis showed that all three byssus are mainly composed of proteins ( $\sim 80 \%$ ), which is similar to $M$. californianus byssus. $P$. nobilis and $A$. pectinata byssus exhibit a similar protein composition, with a glycine (Gly) and alanine (Ala) content that is $2-3$ fold lower than in $M$. californianus byssus, and a complete absence of hydroxyproline (Hyp). This suggests that Pinnidae byssal threads, in contrast to those of Mytilids, are not based on collagen, as previously observed. ${ }^{9,24-26}$ However, they do contain an elevated amount of Pro ( $>10 \mathrm{~mol} \%$ ), which is often associated with intrinsically disordered proteins (IDPs). While the P. fucata byssus contains twice as much Gly as the Pinnidae mussels, it otherwise resembles them and the clear absence of Hyp still differentiates it from the Mytilus collagen-based byssal threads. Pinnidae byssus contains a total amount of metal ions (Fig. 3b) similar to M. edulis ( $4.7 \pm 1.2 \mathrm{mg} \mathrm{g}^{-1}$ for A. pectinata, 

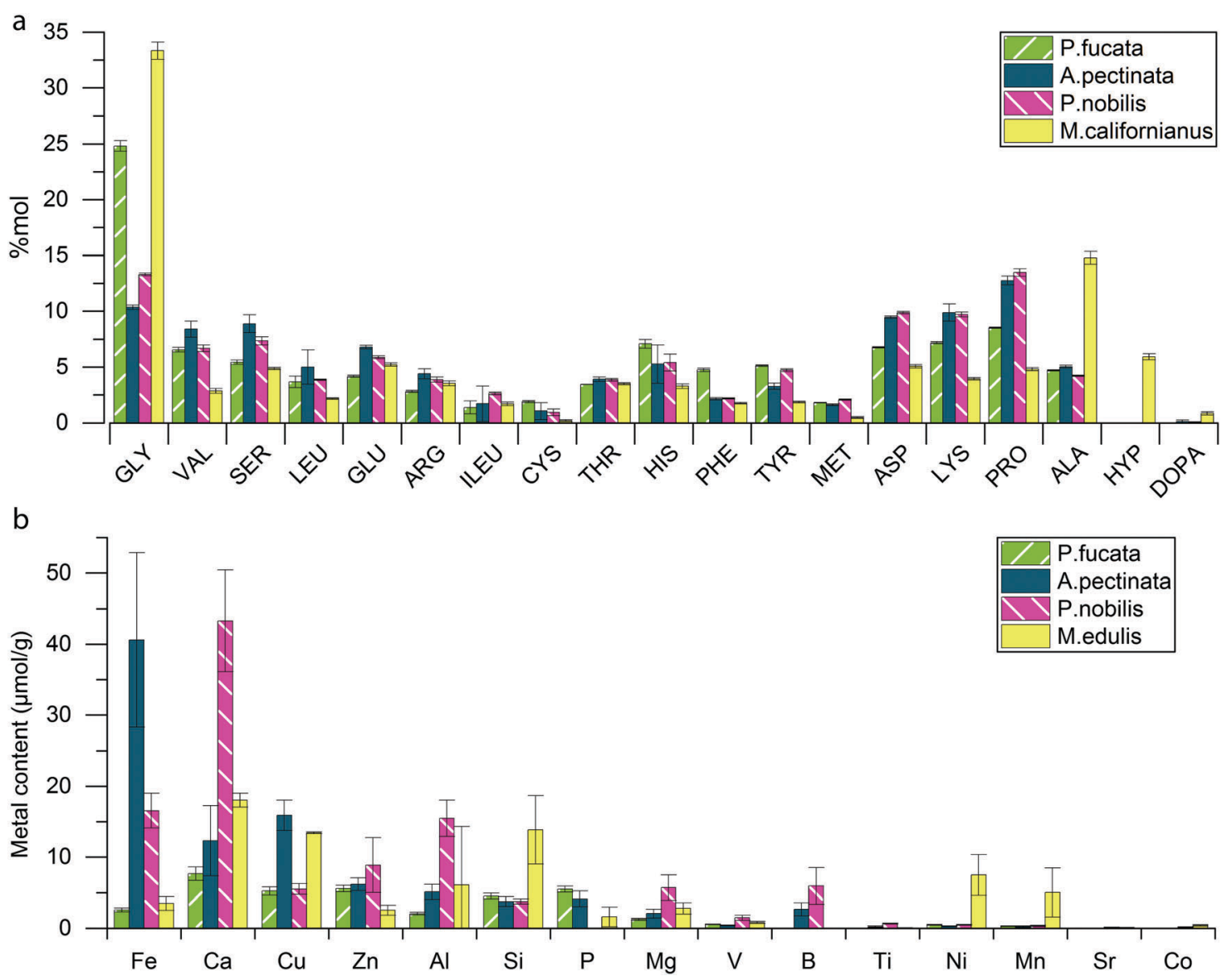

Fig. 3 Comparative compositional analysis of different mussel byssal threads. (a) Relative amino acid composition of the byssus of P. fucata, A. pectinata, P. nobilis and (for comparison) M. californianus, ${ }^{37}$ and (b) metal content in P. fucata, A. pectinata, P. nobilis and M. edulis byssus threads.

$4.0 \pm 0.7 \mathrm{mg} \mathrm{g}^{-1}$ for $P$. nobilis and $3.0 \pm 0.5 \mathrm{mg} \mathrm{g}^{-1}$ for M. edulis), while $P$. fucata seems to contain a bit less $\left(1.6 \pm 0.2 \mathrm{mg} \mathrm{g}^{-1}\right)$. However, it should be emphasized that metal content in byssal threads has been shown to vary considerably between different locations and season, even for threads from the same species, ${ }^{34-36}$ which complicates a purely quantitative comparison between the measurements in this study and with other studies. ${ }^{9}$ Nonetheless, there are notable differences in the relative distribution of different metal ions between the different species.

\section{WAXD/SAXD}

Because amino acid analysis suggests that byssal thread proteins from the three non-mytilid species are not collagenous, we utilized wide angle X-ray diffraction (WAXD) to further investigate the conformation of proteins in the threads, and small angle $\mathrm{X}$-ray diffraction (SAXD) to observe and characterize the higher order organization of proteins. As previously observed, ${ }^{24-26}$ the typical collagen peak at $D=0.287 \mathrm{~nm}$ from Mytilus spp. byssus (arrow on Fig. 4d), corresponding to the rise per amino acid residue of the triple helix, is absent from the diffraction pattern of $P$. nobilis, A. pectinata and P. fucata byssus (Fig. 4a, e and i), as are other peaks arising from the triple helical backbone structure. In fact, there are no sharp peaks visible at all within the WAXD region of the diffraction patterns from $P$. nobilis (Fig. 4e), A. pectinata (Fig. 4a) or P. fucata (Fig. 4i). Rather, the fibers from all three species exhibit a diffuse halo from $Q=10 \mathrm{~nm}^{-1}$ to $25 \mathrm{~nm}^{-1}$, which could originate from randomcoil proteins or also from proteins with a mixture of many secondary structures with various orientations, as found in globular proteins. Notably, however, we do observe a series of sharp and ordered diffraction peaks in the SAXD area (Fig. 4b, $\mathrm{f}$ and $\mathrm{j}$ ) indicating that these proteins apparently arrange regularly at larger length scales. In fact, there is an X-shaped arrangement of diffraction peaks observed in the SAXD pattern from byssal threads from all three species, which is typical for globular protein subunits arranged into a helical superstructure, as in bacterial pili $^{38}$ and actin. ${ }^{39,40}$

Several important characteristics of this helical structure can be directly calculated from the position of the corresponding layer lines of the diffraction pattern. For instance, the layer line of the first meridional diffraction indicates the number of subunits per repeat of the helix and the number of turns/repeat corresponds to the number of layer lines between the meridional diffraction and the neighboring ones. ${ }^{33}$ In $P$. nobilis and $A$. pectinata byssus, the first meridional diffraction on the 2nd layer line indicates that the helix has two subunits per repeat, and the neighboring diffractions on the 3rd layer line 

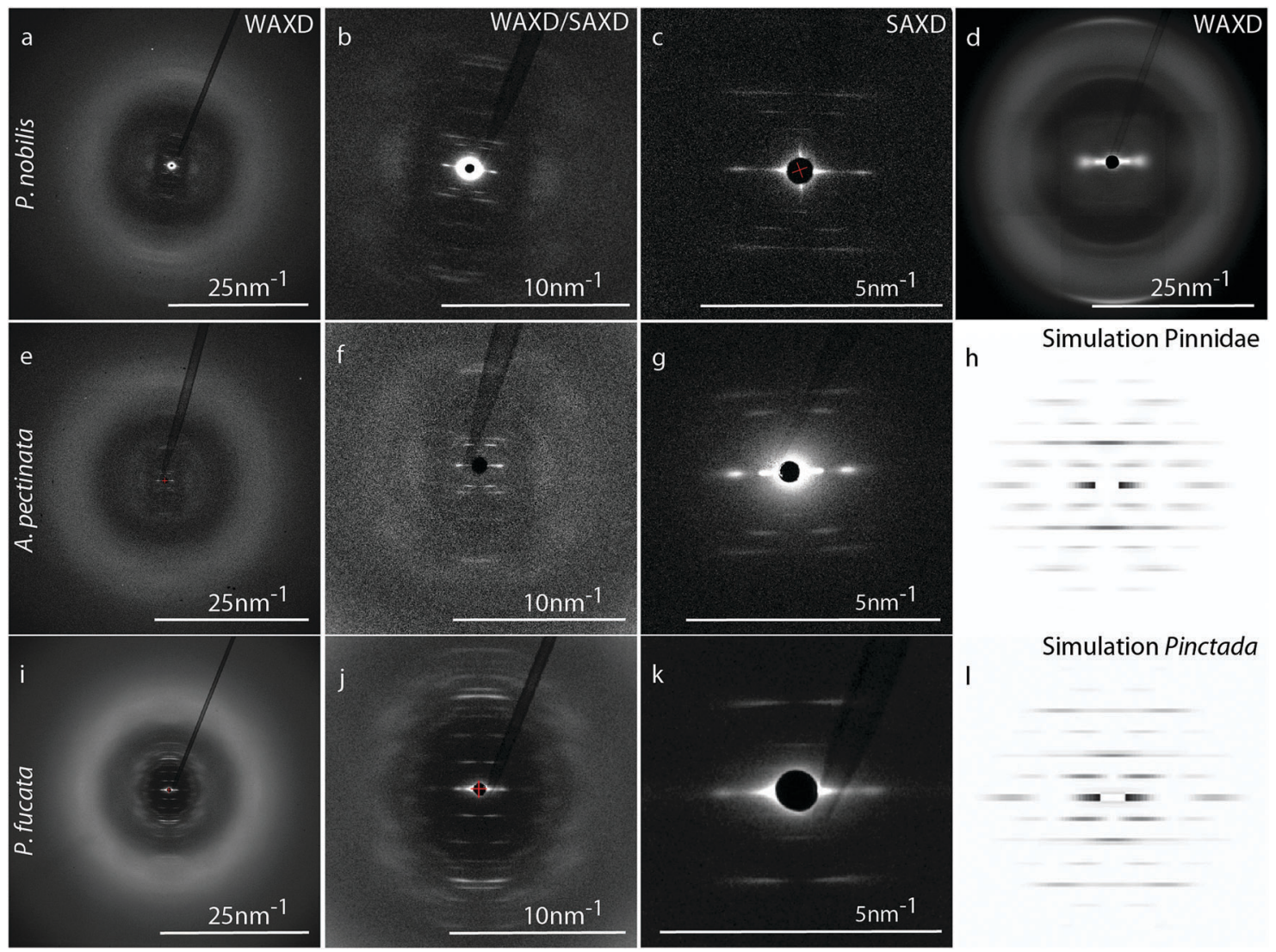

Simulation Pinctada

Fig. 4 Comparative X-ray diffraction analysis of mussel byssal threads. WAXD, zoomed WAXD and SAXD of byssal threads from $P$. nobilis (a-c), A. pectinata $(\mathrm{e}-\mathrm{g})$ and $P$. fucata $(\mathrm{i}-\mathrm{k})$. (d) WAXD of M. edulis byssus. (h and l) Simulation of Pinnidae (h) and Pinctada (l) byssus diffraction pattern.

indicate that the helix possesses one turn per repeat. Thus, both A. pectinata and P. nobilis byssus possess a helical superstructure with two protein subunits per turn. The byssus fibers of $P$. fucata generate a similar SAXD spectrum, except that the diffraction on the 3rd layer line is extinct. However, the distance between layer lines, which indicates the length of the repeat unit, are highly similar between the byssal threads from the three species $(15.70( \pm 0.19) \mathrm{nm}$ for A. pectinata, 15.57 $( \pm 0.20) \mathrm{nm}$ for $P$. nobilis and $16.01( \pm 0.14) \mathrm{nm}$ for $P$. fucata $)$. Differences between the diffraction patterns were investigated using the HELIX software. ${ }^{33}$ To do so, we tuned the different parameters (number and size of subunits, number and relative position of strands) until our simulated spectrum exhibit relative intensities close to the original central diffractions of the SAXS pattern (Fig. 4c, g and k). For the simulated patterns presented in Fig. $4 \mathrm{~h}$ and l, we used the parameters given in Table 1. However, the improvement of the spectra simulation by addition and positioning of a second strand does not necessarily mean that the protein helices really contain two strands, but rather that the shape of the protein is such that it diffracts more like a pair of spheres, rather than like a single sphere (which is the approximation for the shape of the subunit in the HELIX software). This is not unusual considering the complex shape of the globular protein subunits found in bacterial pili, ${ }^{41}$ for example.
Table 1 Parameters used for the simulation of SAXD diffraction pattern of Pinnidae and $P$. fucata byssus

\begin{tabular}{lll}
\hline & Pinnidae & Pinctada \\
\hline Number of subunits levels & 12 & 16 \\
Axial separation of subunits [nm] & 7.8 & 8.05 \\
Number of strands & 2 & 2 \\
Azimuthal shift of second strand $\left[^{\circ}\right]$ & 99 & 90 \\
Axial shift of 2nd strand [nm] & 1.8 & 2.1 \\
Rotation angle between subunits [ $\left.{ }^{\circ}\right]$ & 180 & 180 \\
Monomer center radial position [nm] & 3 & 3 \\
Subunit size (radius) [nm] & 1.5 & 1.6
\end{tabular}

\section{Organisation of protein fibrils into macro-fibers (TEM)}

To gain further support for the hypothesis that threads of P. nobilis, A. pectinata and P. fucata are comprised of globular protein arranged helically into fibers, transmission electron microscopy (TEM) was used to study the nanoscale ultrastructure of the fibers. In order to gain enough contrast, a small defocus was used, leading to a shift in the contrast transfer function allowing the wavelength corresponding to this structure size to be present in the image. ${ }^{42}$ This enabled the observation of a clear fibrillar structure in longitudinal cross-sections of A. fucata and P. nobilis, as well as P. fucata (Fig. 5a, e and i), which is also present on transversal cuts as small dense light circles with a dark-staining core (Fig. $5 \mathrm{a}, \mathrm{f}$ and $\mathrm{j}$ ). This is also 

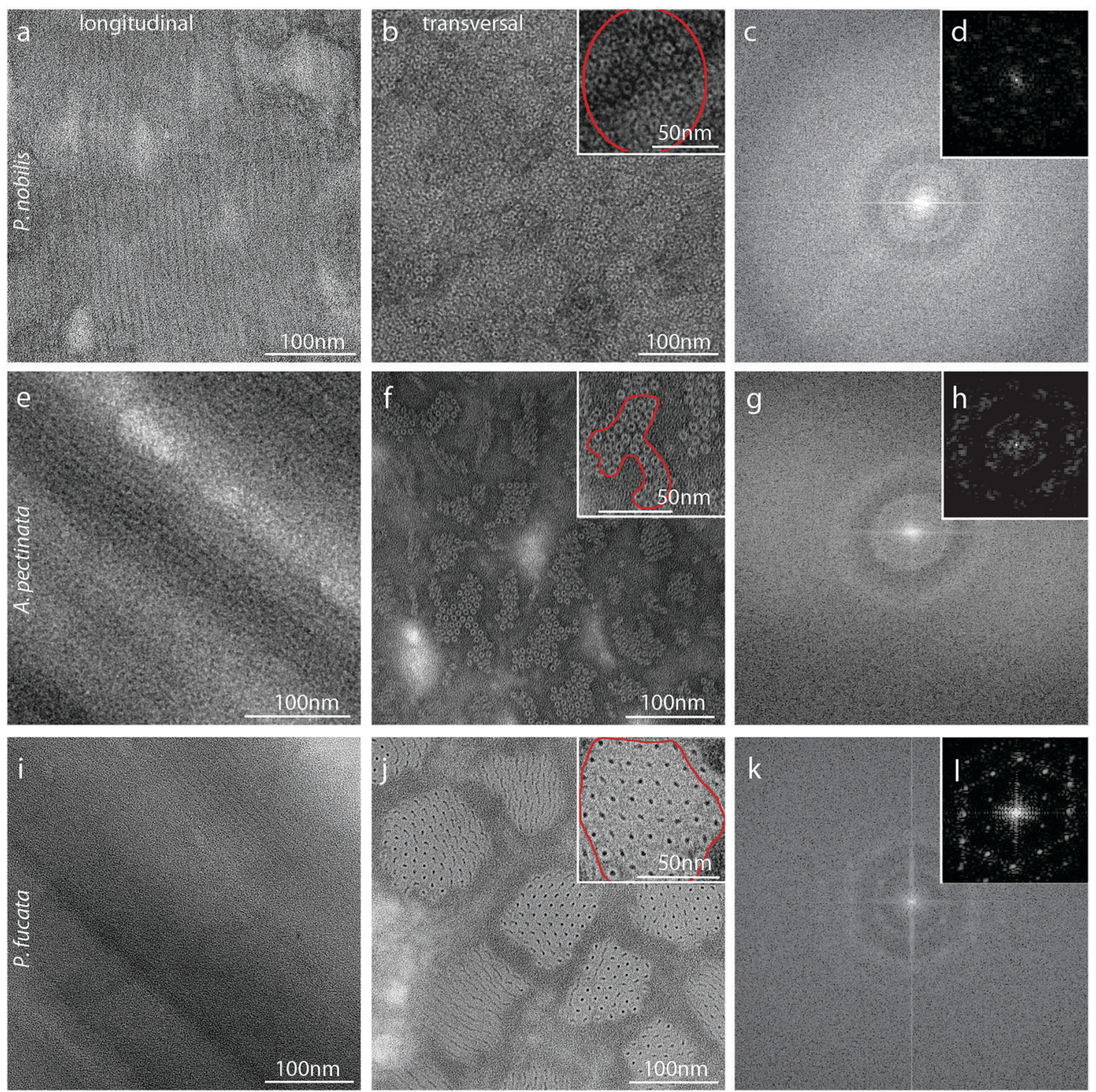

Fig. 5 Comparative transmission electron microscopy (TEM) investigation of different byssal threads. TEM of longitudinal and transversal cut, Fast Fourier transform (FFT) of the transversal cut of $P$. nobilis $(\mathrm{a}-\mathrm{d})$, . pectinata $(\mathrm{e}-\mathrm{h})$, and $P$. fucata $(\mathrm{i}-\mathrm{l})$ byssal threads. The inserts $\mathrm{d}$, h and i show FFT analysis of a small selections (in red on the insert in $\mathrm{b}, \mathrm{f}$ and $\mathrm{j}$ ) of the TEM image of transversal cuts of $P$. nobilis, A. pectinata and $P$. fucata threads.

consistent with previous $\mathrm{TEM}^{43}$ and SEM images of $P$. nobilis byssus. ${ }^{9,43}$ The sizes of the structures we observed are consistent with the fiber sizes predicted from our analysis of the WAXD/SAXD data. In all three species, the helical nanofibrils appear to be embedded in a matrix material, which appears unstructured; however, they are arranged differently in each thread type. In P. nobilis, the helical nanofibrils are dispersed in the matrix, whereas in A. pectinata and P. fucata, nanofibrils are grouped into bundles. In A. pectinata byssus, these fibrils are closely packed, while in $P$. nobilis and P. fucata byssus, the packing is looser. A Fast Fourier Transform (FFT) of the TEM image allows a better characterization of the packing, and shows that locally, the fibrils in byssus of all three species present a well ordered hexagonal packing (Fig. $5 \mathrm{~d}, \mathrm{~h}$ and l), with a distance between fibrils of $10.6( \pm 0.4) \mathrm{nm}$ in P. nobilis fibers, $8.1( \pm 0.7) \mathrm{nm}$ in A. pectinata fibers and $10.4( \pm 0.6) \mathrm{nm}$ in
P. fucata fibers (calculated from the FFT). On larger length scales, however, the organisation was lost (Fig. 5c, g and k). Finally, the contrast between fibrils and matrix in $P$. fucata byssus differs from A. pectinata and $P$. nobilis byssus. All fibers present a porous matrix between the bundles, but the matrix in P. nobilis and A. pectinata is stained darker than in P. fucata, compared to the fibrils, which may be due to compositional differences, as supported by amino acid analysis.

\section{Discussion}

Our investigation reveals that mussel byssal threads of the three species chosen from the order Ostreida possess a similar composition and ultrastructure to one another, which is entirely different from threads of Mytiloida mussels (Fig. 6). 


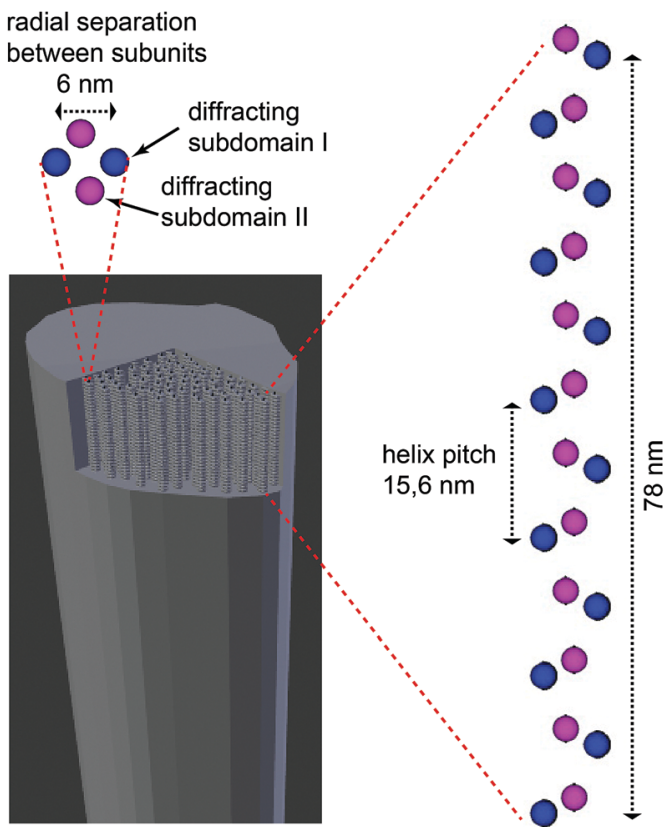

b

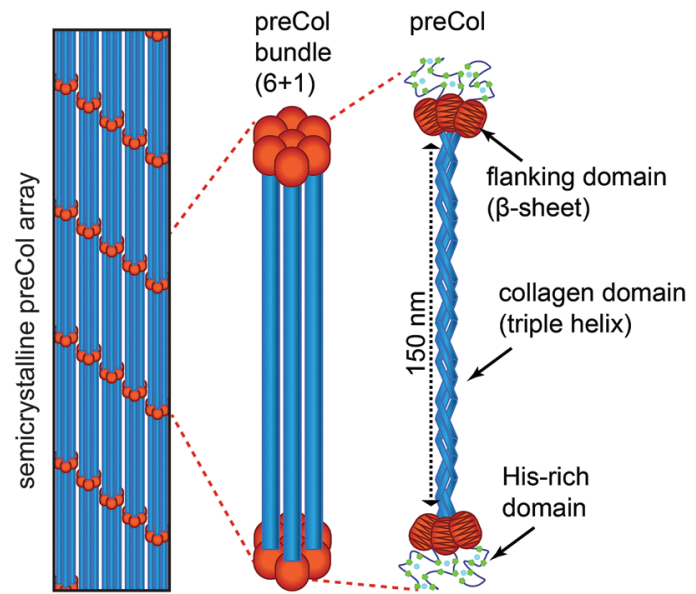

Fig. 6 Proposed arrangement of the structural proteins in Pinna byssus. (a) Minimal model of Ostreida byssus superhelix indicating diffraction centers based on SAXD measurements and simulations. Subdomains I and II are likely to belong to the same protein. (b) Current model of protein arrangement in Mytillus spp. byssus.

Ostreida mussel byssus appears to be comprised of distinct nanofibrils assembled from globular protein subunits organized into a helical structure (Fig. 6a). As already suggested in the literature, ${ }^{9,24-26}$ our compositional analysis indicates that Ostreida byssus fibers are not likely to be comprised of collagenous proteins. This conjecture was confirmed convincingly via analysis of WAXD and SAXD patterns from the threads of all three Ostreida species. WAXD patterns showed absolutely no evidence for the presence of triple helical collagen structure or any other periodic secondary structure, while SAXD patterns clearly indicate the presence of helical fibers, supported by TEM imaging.
This peculiar way of building fibers is shared between the three species investigated, with slight differences. There seems to be more similarities between the byssus ultrastructure of $P$. nobilis and A. pectinata, which belong to the same superfamily, than between them and $P$. fucata, which is less closely related. Indeed, $A$. pectinata and $P$. nobilis byssal threads exhibit a similar biochemical composition, have the same size building blocks (as determined by SAXD analysis), and present very similar TEM images. The major difference between the two based on these data is the grouping of nanofibrils into bundles in the byssus of $A$. pectinata, while the nanofibers are more dispersed in $P$. nobilis byssus. This results in a difference in the fibril/matrix ratio that may be responsible for the slight differences in amino acid composition since the matrix is likely to be made by different protein(s) than the fibrils, as is the case in Mytilus spp. byssus. ${ }^{44}$ In contrast, the distances between subunits of the protein helix of $P$. fucata byssus are slightly larger than those in Pinnidae byssus, which likely indicates that the protein subunits are slightly bigger. In any case, these findings strongly suggest that the Pinnidae mussels possess a very similar protein subunit for building the helical nanofibrils based on the fact that they are much closer on the evolutionary tree, whereas, although $P$. fucata has retained the same general helical structure, the protein subunit is appreciably different from that of the Pinnidae. Investigations are underway to determine the sequence of these proteins; however, it has already been reported that byssal threads from Pinctada spp. may contain a thrombospondin-like protein, ${ }^{29}$ which is consistent with our model of globular protein building blocks. Thus, it stands to reason that the Pinnidae byssus building blocks may be similar. However, this must be further examined.

In spite of the differences between P. fucata and Pinnidae mussel byssus, they are much more similar to one another than to Mytilid byssus. Indeed, Pinnidae and Pteriidae both belong to the same order (Ostreida), while Mytilus spp. belongs to a different order (Mytiloida) (Fig. 2). The existence of morphological variations within different orders of the same infraclass is confirmed by Anomia - like Pinnidae and Pinctada, Anomia belongs to the Pteriomorphia, but it possesses a mineralized byssus that is completely different, since it is $90 \%$ calcified. These evolutionary divergences in nanostructures might actually be linked to the living environment of the mussel as previously suggested: ${ }^{9}$ Ostreida prefers calm water and might not need the special chemical/structural features that allow Mytilus spp. mussels to survive in harsh environment with crashing waves. Even within Mytilus spp., some species (e.g. Mytilus californianus) have apparently evolved to survive in higher wave impact zones than other related species (e.g. Mytilus edulis and Mytilus galloprovincialis). ${ }^{45}$ The byssus macrostructure (number, thickness and length of threads) also seems to be influenced by the mode of anchoring. For example, Mytilus spp. and Pinctada spp. are anchored on hard surfaces (rocks, coral), and therefore, they use a small amount of thick and short threads, whereas A. pectinata and $P$. nobilis evolved a different anchoring strategy as their byssus is buried in muddy or sandy sediments. ${ }^{9}$ This may explain why they have an exceptionally 
high amount of long and thin threads (up to 30000 ), whose attachment relies more on entanglement rather than adhesion. Thus, as with the sheer diversity of different spider silks adapted to different physical requirements, ${ }^{7}$ many different forms of byssus have appeared throughout evolution. It seems likely that their properties may reflect both the systematic position within the class Bivalvia and the pressures of the ecological niche in which they live. This conclusion based on the micronano structure of byssus threads from related species seems to confirm a similar hypothesis suggested by Marcotte and co-workers based on compositional and mechanical analysis. ${ }^{9}$

It is additionally notable, that similar to Mytilus spp. byssus, byssal threads of Ostreida mussels contain an elevated content of inorganic ions, especially iron and calcium, although seasonal and regional dependence of inorganic content in byssus threads ${ }^{46,47}$ prohibit detailed or quantitative comparison between species and with other studies. While it is well established that transition metal ions, such as $\mathrm{Fe}^{3+}$ and $\mathrm{Zn}^{2+}$ play a critical role in determining the tough and self-healing behaviour of Mytilus spp. byssal threads by forming metal coordination bonds with specific amino acid ligand in the byssus proteins (e.g. Histidine and DOPA) ${ }^{48}$ the potential role of ions in the assembly and performance of Pinnidae byssus is not yet clear. Due to the very low DOPA content and the high content in charged amino acids, it was previously hypothesized that assembly and mechanics of $P$. nobilis byssus may rely on electrostatic interaction. Along these lines, it was recently reported for $P$. fucata that $\mathrm{Ca}^{2+}$ may induce thread assembly and that metal removal reduced mechanical performance of threads $;^{28}$ thus, it seems feasible that they may play a similar role in Pinnidae byssus given their structural and compositional similarity to $P$. fucata threads. While the potential role of calcium ions remains to be established in Pinnidae threads, Fe-DOPA crosslinks have been reported to play a key role at the interface between A. pectinata byssus threads and soft tissue. ${ }^{49}$

Perhaps the most perplexing finding of this study is the peculiar fibrillar superstructure in the Ostreida mussel byssus, which is built up from globular proteins arranged in a very welldefined helix (Fig. 6a). Helical structures per se are not unusual in extraorganismic protein fibers. For example, fibrillar collagen is comprised of right-handed triple helices of three protein chains with left handed poly-proline II helical conformation, ${ }^{50}$ while coiled coil alpha helices are dominant in the intermediate filaments which comprise materials such as wool, ${ }^{51}$ gastropod egg cases ${ }^{52}$ and even hagfish slime. ${ }^{53,54}$ In fact, the byssal threads of the giant clam Tridacna maxima were discovered to consist of proteins arranged in a four stranded alpha helical coiled coil. ${ }^{20}$ However, the discovery of a supramolecular helix of globular proteins that was deduced here from the SAXD patterns from the Ostreida mussel byssal threads is, as far as we know, unprecedented in an externally secreted macroscopic biological fiber. The only analogous structures fabricated extracellularly are single nanofibrils produced by bacteria known as pili. In some cases, bacterial pili can be used as an anchor to resist flow, as in the case of $E$. coli living in the urethra during urinary infections. In this case, the helical structure of the bacterial pili handles load from fluid flow by extending like a spring. ${ }^{55,56}$ The helical structure of the nanofibrils within the Ostreida byssal threads might perform in a similar manner in its role as a sedimentary anchor, but on a macroscopic scale. In support of this hypothesis, single molecule force spectroscopy measurement of single bacterial pili with atomic force microscopy (AFM) exhibit an initial stiff region followed by a long yield plateau and finally a post-yield stiffening region, ${ }^{57}$ which is reminiscent of previously published tensile stress-strain curves of $P$. nobilis byssus fibers. ${ }^{9}$ In single bacterial pili, the yield plateau was attributed to the unravelling of the higher order helix comprised of many globular subunits, while the post-yield stiffening was surmised to elongation of the unfolded helix. ${ }^{57}$ At the macroscopic scale, the yield plateau observed in mechanical tests of $P$. nobilis threads could represent the successive unravelling of many helical nanofibrils or from sliding of subunits in the matrix for example. Unfolding and elongation of alpha helical coiled coils results in a similar macroscopic stress-strain curve in materials such as wool, ${ }^{58}$ hagfish slime ${ }^{53}$ and whelk egg capsules ${ }^{52}$ adding further support to this putative structure-function model. However, verifying this conjecture must await further investigation - perhaps by coupling XRD with in situ mechanical testing, as has been successful with Mytilus spp. byssal threads. ${ }^{18,59,60}$

\section{Conclusion}

Through an in-depth comparative investigation of composition and ultrastructure, we have determined that byssal threads from Ostreida mussels including $P$. nobilis, A. pectinata and P. fucata, exhibit a peculiar protein superstructure in which globular protein building blocks are organized into a helical structure. Globular protein helices were not previously observed as a structural motif in macroscopic biological fibers and are extremely different from the collagen-based structure of Mytilus spp. byssal threads. This finding suggests a large evolutionary divergence in byssus design, which may have occurred at the separation of Mytiloida and Ostreida into distinct groups. While we are cautious in our interpretation of how this unusual supramolecular fibrillar structure might be related to the mechanical performance, similarities between previously published mechanical data from $P$. nobilis and single molecule data of bacterial pili suggest that unravelling of the superhelix and unfolding of globular protein structure may be involved in the extended yield plateau and high extensibility of the fibers. Indeed, a similar mechanism is at play in the mechanical performance of macroscopic materials based on coils coils (e.g. wool, hagfish slime, whelk egg capsule). Regardless of the exact molecular mechanism, the long history of human exploitation of Pinna nobilis byssus in the form of sea silk suggests that it is worth diving more deeply into this question. Indeed, these investigations may inspire new polymeric materials, as is the case with Mytilus spp. byssus, and may shed further light on the role of the byssus in the evolution of bivalves. 


\section{Conflicts of interest}

There are no conflicts to declare.

\section{Acknowledgements}

We thank the crew of Alchimie-Méditerranée (A. Garcia, C. Dumas, L. Gilletta de St-Joseph) for the collection of Pinna nobilis byssus and members of the Observatoire Océanologique de Villefranchesur-Mer (R. Lasbleiz, K. Testard, D. Luquet) for their logistic support. We also thank J. M. Squire (University of Bristol) for his help with the HELIX analysis software, J. Choi for help in acquiring $A$. pectinata and $P$. fucata threads, R. Pitschke (MPIKG) for assistance with acquiring TEM images, J. Steffen (MPIKG) for the composition measurements and Stefan Siegel and Chenghao Li (MPIKG-MuSpot) for technical support. This research was supported by the Max Planck Society, the Deutsche Forschungsgemeinschaft (DFG) (HA6369/4-1), the Observatoire des Sciences de l'Univers Terre-Homme-Environnement-Temps-Astronomie (OSU-theta, 2017), the European Marine Biological Resources Center (EMBRC, AAP2017) and the National Research Foundation of Korea (NRF) funded by the Ministry of Science, ICT \& Future Planning (NRF-2015K1A3A1A59074243: KONNECT). Open Access funding provided by the Max Planck Society.

\section{Notes and references}

1 J. Gosline, M. Lillie, E. Carrington, P. Guerette, C. Ortlepp and K. Savage, Elastic proteins: biological roles and mechanical properties, Philos. Trans. R. Soc., B, 2002, 357(1418), 121-132.

2 A. Kivelio, P. Dekoninck, M. Perrini, C. E. Brubaker, P. B. Messersmith and E. Mazza, et al., Mussel mimetic tissue adhesive for fetal membrane repair: initial in vivo investigation in rabbits, Eur. J. Obstet. Gynecol. Reprod. Biol., 2013, 171(2), 240-245.

3 M. Yang, K. Yamauchi, M. Kurokawa and T. Asakura, Design of silk-like biomaterials inspired by mussel-adhesive protein, Tissue Eng., 2007, 13(12), 2941-2947.

4 Y. Liu, S. Ling, S. Wang, X. Chen and Z. Shao, Thixotropic silk nanofibril-based hydrogel with extracellular matrix-like structure, Biomater. Sci., 2014, 2(10), 1338-1342.

5 G. V. Guinea, M. Elices, G. R. Plaza, G. B. Perea, R. Daza and C. Riekel, et al., Minor Ampullate Silks from Nephila and Argiope Spiders: Tensile Properties and Microstructural Characterization, Biomacromolecules, 2012, 13(7), 2087-2098.

6 T. D. Sutherland, J. H. Young, S. Weisman, C. Y. Hayashi and D. J. Merritt, Insect Silk: One Name, Many Materials, Annu. Rev. Entomol., 2010, 55(1), 171-188.

7 T. A. Blackledge, N. Scharff, J. A. Coddington, T. Szüts, J. W. Wenzel and C. Y. Hayashi, et al., Reconstructing web evolution and spider diversification in the molecular era, Proc. Natl. Acad. Sci. U. S. A., 2009, 106(13), 5229-5234.

8 C. Y. Hayashi, N. H. Shipley and R. V. Lewis, Hypotheses that correlate the sequence, structure, and mechanical properties of spider silk proteins, Int. J. Biol. Macromol., 1999, 24(2), 271-275.
9 Z. Bouhlel, B. Genard, N. Ibrahim, E. Carrington, J. M. F. Babarro and A. Lok, et al., Interspecies comparison of the mechanical properties and biochemical composition of byssal threads, J. Exp. Biol., 2017, 220(6), 984-994.

10 S. L. Brazee and E. Carrington, Interspecific Comparison of the Mechanical Properties of Mussel Byssus, Biol. Bull., 2006, 211(3), 263-274.

11 E. Carrington and J. M. Gosline, Mechanical design of mussel byssus: load cycle and strain rate dependency, Am. Malacol. Bull., 2004, 18(1/2), 135-142.

12 J. E. Smeathers and J. F. V. Vincent, Mechanical Properties of Mussel Byssus Threads, J. Molluscan Stud., 1979, 45(2), 219-230.

13 N. Aldred, T. Wills, D. N. Williams and A. S. Clare, Tensile and dynamic mechanical analysis of the distal portion of mussel (Mytilus edulis) byssal threads, J. R. Soc., Interface, 2007, 4(17), 1159-1167.

14 C. N. Z. Schmitt, Y. Politi, A. Reinecke and M. J. Harrington, Role of Sacrificial Protein-Metal Bond Exchange in Mussel Byssal Thread Self-Healing, Biomacromolecules, 2015, 16(9), 2852-2861.

15 C. N. Z. Schmitt, A. Winter, L. Bertinetti, A. Masic, P. Strauch and M. J. Harrington, Mechanical homeostasis of a DOPAenriched biological coating from mussels in response to metal variation, J. R. Soc., Interface, 2015, 12(110), 20150466.

16 N. Holten-Andersen, M. J. Harrington, H. Birkedal, B. P. Lee, P. B. Messersmith and K. Y. C. Lee, et al., pH-induced metalligand cross-links inspired by mussel yield self-healing polymer networks with near-covalent elastic moduli, Proc. Natl. Acad. Sci. U. S. A., 2011, 108(7), 2651-2655.

17 M. Enke, S. Bode, J. Vitz, F. H. Schacher, M. J. Harrington and M. D. Hager, et al., Self-healing response in supramolecular polymers based on reversible zinc-histidine interactions, Polymer, 2015, 69, 274-282.

18 A. Reinecke, L. Bertinetti, P. Fratzl and M. J. Harrington, Cooperative behavior of a sacrificial bond network and elastic framework in providing self-healing capacity in mussel byssal threads, J. Struct. Biol., 2016, 196(3), 329-339.

19 A. A. Arnold, F. Byette, M.-O. Séguin-Heine, A. LeBlanc, L. Sleno and R. Tremblay, et al., Solid-State NMR Structure Determination of Whole Anchoring Threads from the Blue Mussel Mytilus edulis, Biomacromolecules, 2013, 14(1), 132-141.

20 A. Miserez, Y. Li, J. Cagnon, J. C. Weaver and J. H. Waite, Four-Stranded Coiled-Coil Elastic Protein in the Byssus of the Giant Clam, Tridacna maxima, Biomacromolecules, 2012, 13(2), 332-341.

21 J. R. Eltzholtz and H. Birkedal, Architecture of the Biomineralized Byssus of the Saddle Oyster (Anomia sp.), ResearchGate, 2009, 85(9), 590-600.

22 B. Laufer, The Story of the Pinna and the Syrian Lamb, J. Am. Folk., 1915, 28(108), 103-128.

23 F. Maeder, Sea-silk in aquincum: first production proof in antiquity, in Purpureae Vestes II. Vestidos, textiles y tintes: Estudios sobre la producción de bienes de consumo en la Antigüedad, ed. C. Alfaro, L. Karali, Universitat de Valencia, 2008, pp. 109-118. 
24 J. P. Pujol, M. Rolland, S. Larsy and S. Vinet, Comparative study of the amino acid composition of the byssus in some common bivalve molluscs, Comp. Biochem. Physiol., 1970, 34(1), 193-201.

25 J. P. Pujol, Le complexe byssogène des mollusques bivalves, histochimie comparée des secrétions chez Mytilus edulis L. et Pinna nobilis L., Bull. Soc. Linn. Normandie, 1967, 8, 308-331.

26 S. Fitton Jackson, F. C. Kelly, A. C. North, J. T. Randall, W. E. Seeds, M. Watson, et al., The Byssus Threads of Mytilus edulis and Pinna nobilis, in Nature and Structure of Collagen, ed. J. T. Randall and F. R. S. Jackson, Butterworths Scientific Publications, London, 1953, pp. 106-116.

27 J. J. Hwang, T. Yamakawa and I. Aoki, Growth of wild pearl oysters Pinctada fucata, Pinctada margaritifera and Pinctada sugillata (Bivalvia: Pteriidae) in Taiwan, Fish. Sci., 2007, 73(1), 132-141.

28 C. Liu, L. Xie and R. Zhang, $\mathrm{Ca}^{2+}$ Mediates the Self-Assembly of the Foot Proteins of Pinctada fucata from the Nanoscale to the Microscale, Biomacromolecules, 2016, 17(10), 3347-3355.

29 C. Liu, S. Li, J. Huang, Y. Liu, G. Jia and L. Xie, et al., Extensible byssus of Pinctada fucata: $\mathrm{Ca}^{2+}$-stabilized nanocavities and a thrombospondin-1 protein, Sci. Rep., 2015, $5,15018$.

30 J. G. Carter, C. R. Altaba, L. C. Anderson, R. Araujo, A. S. Biakov, A. E. Bogan, et al., A Synoptical Classification of the Bivalvia (Mollusca), Paleontological Contributions, 2011, Number 4, pp. 1-47.

31 O. Paris, C. Li, S. Siegel, G. Weseloh, F. Emmerling and H. Riesemeier, et al., A new experimental station for simultaneous X-ray microbeam scanning for small- and wideangle scattering and fluorescence at BESSY II, J. Appl. Crystallogr., 2007, 40(s1), 466-470.

32 G. Benecke, W. Wagermaier, C. Li, M. Schwartzkopf, G. Flucke and R. Hoerth, et al., A customizable software for fast reduction and analysis of large X-ray scattering data sets: applications of the new DPDAK package to small-angle $\mathrm{X}$-ray scattering and grazing-incidence small-angle X-ray scattering, J. Appl. Crystallogr., 2014, 47(Pt 5), 1797-1803.

33 C. Knupp and J. M. Squire, HELIX: a helical diffraction simulation program, J. Appl. Crystallogr., 2004, 37(5), 832-835.

34 P. Szefer, S. W. Fowler, K. Ikuta, F. P. Osuna, A. A. Ali and B.-S. Kim, et al., A comparative assessment of heavy metal accumulation in soft parts and byssus of mussels from subarctic, temperate, subtropical and tropical marine environments, Environ. Pollut., 2006, 139(1), 70-78.

35 P. Szefer, K. Frelek, K. Szefer, C.-B. Lee, B.-S. Kim and J. Warzocha, et al., Distribution and relationships of trace metals in soft tissue, byssus and shells of Mytilus edulis trossulus from the southern Baltic, Environ. Pollut., 2002, 120(2), 423-444.

36 G. M. Moeser and E. Carrington, Seasonal variation in mussel byssal thread mechanics, J. Exp. Biol., 2006, 209(10), 1996-2003.

37 C. N. Z. Schmitt, The Role of Protein Metal Complexes in the Mechanics of Mytilus Californianus Byssal Threads, University of Potsdam, Potsdam, 2015.
38 W. Folkhard, D. A. Marvin, T. H. Watts and W. Paranchych, Structure of polar pili from Pseudomonas aeruginosa strains K and O, J. Mol. Biol., 1981, 149(1), 79-93.

39 G. M. Cooper, Structure and Organization of Actin Filaments, The Cell: A Molecular Approach, Sinauer Associates, Sunderland (MA), 2nd edn, 2000.

$40 \mathrm{~J}$. Hanson and J. Lowy, The structure of F-actin and of actin filaments isolated from muscle, J. Mol. Biol., 1963, 6(1), 46-60.

41 M. Gorgel, J. J. Ulstrup, A. Bøggild, N. C. Jones, S. V. Hoffmann and P. Nissen, et al., High-resolution structure of a type IV pilin from the metal-reducing bacterium Shewanella oneidensis, BMC Struct. Biol., 2015, 15, 4.

42 D. B. Williams and C. B. Carter, Transmission Electron Microscopy: A Textbook for Materials Science, Springer US, 2nd edn, 2009.

43 A. Diana, M. Reguzzoni, T. Congiu, A. Rescigno, F. Sollai and M. Raspanti, The byssus threads of Pinna nobilis: a histochemical and ultrastructural study, Eur. J. Histochem., 2017, 61(4), 280-286.

44 J. Sagert and J. H. Waite, Hyperunstable matrix proteins in the byssus of Mytilus galloprovincialis, J. Exp. Biol., 2009, 212(14), 2224-2236.

45 M. J. Harrington and J. H. Waite, Holdfast heroics: comparing the molecular and mechanical properties of Mytilus californianus byssal threads, J. Exp. Biol., 2007, 210(24), 4307-4318.

46 T. L. Coombs and P. J. Keller, Mytilus byssal threads as an environmental marker for metals, Aquat. Toxicol., 1981, 1(5), 291-300.

47 P. Szefer, B.-S. Kim, C.-K. Kim, E.-H. Kim and C.-B. Lee, Distribution and coassociations of trace elements in soft tissue and byssus of Mytilus galloprovincialis relative to the surrounding seawater and suspended matter of the southern part of the Korean Peninsula, Environ. Pollut., 2004, 129(2), 209-228.

48 E. Degtyar, M. J. Harrington, Y. Politi and P. Fratzl, The Mechanical Role of Metal Ions in Biogenic Protein-Based Materials, Angew. Chem., Int. Ed., 2014, 53(45), 12026-12044.

49 H. Y. Yoo, M. Iordachescu, J. Huang, E. Hennebert, S. Kim and S. Rho, et al., Sugary interfaces mitigate contact damage where stiff meets soft, Nat. Commun., 2016, 7, 11923.

50 L. Pauling and R. B. Corby, The structure of fibrous proteins of the collagen gelatin group, Proc. Natl. Acad. Sci. U. S. A., 1951, 37, 272-281.

51 L. C. Gruen and E. F. Woods, Structural studies on the microfibrillar proteins of wool. Interaction between alphahelical segments and reassembly of a four-chain structure, Biochem. J., 1983, 209(3), 587-595.

52 M. J. Harrington, S. S. Wasko, A. Masic, F. D. Fischer, H. S. Gupta and P. Fratzl, Pseudoelastic behaviour of a natural material is achieved via reversible changes in protein backbone conformation, J. R. Soc., Interface, 2012, 9(76), 2911-2922.

53 D. S. Fudge, K. H. Gardner, V. T. Forsyth, C. Riekel and J. M. Gosline, The Mechanical Properties of Hydrated 
Intermediate Filaments: Insights from Hagfish Slime Threads, Biophys. J., 2003, 85(3), 2015-2027.

54 E. A. Koch, R. H. Spitzer, R. B. Pithawalla and D. A. D. Parry, An unusual intermediate filament subunit from the cytoskeletal biopolymer released extracellularly into seawater by the primitive hagfish (Eptatretus stouti), J. Cell Sci., 1994, 107, 3133-3144.

55 M. K. Hospenthal, A. Redzej, K. Dodson, M. Ukleja, B. Frenz and C. Rodrigues, et al., Structure of a Chaperone-Usher Pilus Reveals the Molecular Basis of Rod Uncoiling, Cell, 2016, 164(1-2), 269-278.

56 E. Fällman, S. Schedin, J. Jass, B.-E. Uhlin and O. Axner, The unfolding of the $\mathrm{P}$ pili quaternary structure by stretching is reversible, not plastic, ЕMBO Rep., 2005, 6(1), $52-56$.
57 E. Miller, T. Garcia, S. Hultgren and A. F. Oberhauser, The Mechanical Properties of E. coli Type 1 Pili Measured by Atomic Force Microscopy Techniques, Biophys. J., 2006, 91(10), 3848-3856.

58 L. Kreplak, J. Doucet, P. Dumas and F. Briki, New Aspects of the $\alpha$-Helix to $\beta$-Sheet Transition in Stretched Hard $\alpha$-Keratin Fibers, Biophys. J., 2004, 87(1), 640-647.

59 M. J. Harrington, H. S. Gupta, P. Fratzl and J. H. Waite, Collagen insulated from tensile damage by domains that unfold reversibly: in situ X-ray investigation of mechanical yield and damage repair in the mussel byssus, J. Struct. Biol., 2009, 167(1), 47-54.

60 S. Krauss, T. H. Metzger, P. Fratzl and M. J. Harrington, SelfRepair of a Biological Fiber Guided by an Ordered Elastic Framework, Biomacromolecules, 2013, 14(5), 1520-1528. 